weissen zarten inneren Theile. Nach Clarke's gemachten Erfahrungen dient sie den Kosacken zu einem vortrefflichen Nahrungsmittel.

Die Typha wird gerade wie der Spargel geschnitten, wenn die jungen Schösse emporsprossen. Sie wird geschält, mit Salzwasser abgekocht und wie Spargel behandelt und kann alle dessen Zubereitungen erfahren. Demnach kann der Rohrkolben, der bis jetzt meist nur als Zierrath unserer Fluss-, See- und Teichufer diente, in der Folge weitere Nutzanwendung finden. (Pharm. Journ. and Transact. - Pharm Centrbl. 1848. Nr.35.)

$B$.

\title{
Analytische Stickstoffbestimmung.
}

Nach J. Mitchell soll man statt der von Peligot vorgeschlagenen Kalklösung durch Zucker, eine schwache Aetznatronlauge von 1,018 spec. Gew. anwenden und übrigens wie Pelig ot angegeben hat, verfahren, nämlich das nach der Varrentrap -Will'schen Methode erhal. tene Ammoniak in Schwefelsäure auffangen und den Rest, der freien Schwefelsäure mit dieser Lauge sattigen. Die Bestimmung der verbrauchten Menge an Alkali soll mittelst eines Sch uster'schen Alkalimeters, nicht mit der Burette, geschehen. Das Kennzeichen der Neutralität soll stati; der Bläuung von Lackmus die Farbenveränderung einesi Campechenholz-Decocts sein, wovon einige Tropfen der sauren Fluissigkeit eine gelblich braune Farbe ertheilen. die durch die geringste Menge überschuissigen Alkalis schwarzblau wird. (Quart. Journ. of the Chem. Soc of Lond. - Pharm. Centrbl. 1845. No. 43.)

$B$.

\section{Zersetzungsproducte des Cyanäthyls durch Einwir- kung von Kalium.}

Frankland und Kolbe versuchten, das Aethyl aus dem Cyanäthyl mittelst Kaliums abzuscheiden und erwarteten um so mehr einen glücklichen Erfolg, als das Kalium schon bei gewöhnlicher Temperatur sehr stark auf das Cyanäthyl einwirkte und Cyankalium in reichlicher Menge sich bildete. Das dabei von dem blank hleibenden Kalium und ununterbrochen sich entwickelnde brennbare in Wasser unlösliche Gas war aber nicht das gesuchte Aethyl, da die Analyse ergab, dass es aus Kohlenstoff und Wasserstoff im Verhäliniss von $2: 3$ bestand. Es musste nach Zusammenfassung aller bei der Analyse 